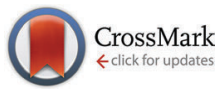

Cite this: New J. Chem., 2015 39, 2306

Received (in Montpellier, France) 28th November 2014, Accepted 14th January 2015

DOI: $10.1039 / c 4 n j 02178 a$

www.rsc.org/njc

\title{
Evaluation of the nitroaldol reaction in the presence of metal ion-crosslinked alginates $\dagger$
}

\author{
Dennis Kühbeck, $\ddagger^{\mathrm{a}}$ Judith Mayr, $\ddagger^{\mathrm{a}}$ Marleen Häring, $\ddagger^{\mathrm{a}}$ Martin Hofmann, ${ }^{\mathrm{a}}$ \\ Françoise Quignard ${ }^{\mathrm{b}}$ and David Díaz Díaz ${ }^{\text {ac }}$
}

\begin{abstract}
Understanding the ability of biopolymers to promote selective $\mathrm{C}-\mathrm{C}$ bond formation could provide important insights into the molecular mechanisms underlying evolution, and could help in the design of safer and "greener" catalysts in the future. This work describes the preparation of metal ion-crosslinked alginate materials and the evaluation of their potential catalytic activity towards the Henry (nitroaldol) reaction between a variety of aldehydes and nitroalkanes. The results demonstrated broad substrate specificity and a remarkable influence of the solvent nature, metal ion, and physical state of the alginate-based catalysts. In this sense, $\mathrm{Ca}^{2+}$-alginate hydrogel beads in DMSO used as a heterogeneous and recyclable catalyst were found to be the most efficient system, although the reaction could also proceed in an aqueous medium. Moreover, both small and large-scale model reactions between 4-nitrobenzaldehyde and nitromethane were performed successfully at room temperature. The possibility of coupling the reaction with an enzymatic resolution of the so-obtained $\beta$-nitroalcohol products was also assessed. All materials were characterized using different techniques including, among others, FT-IR, TGA, ICP-OES, and FE-SEM.
\end{abstract}

\section{Introduction}

The gradual shift from the utilization of petrochemical-based feedstocks to inexpensive eco-friendly resources and sustainable processes is the unavoidable consequence of the growing concern for the environment and the stricter regulations of toxic pollutants. ${ }^{1}$ In this context, the use of biopolymers have attracted increasing attention during the last decade for numerous applications in different industries including, among others, automotive, construction, textile, agriculture, optoelectronics, defense, foodstuffs, health care, biomedical and pharmaceutical products. ${ }^{2}$ More recently, the study of natural polysaccharides as promising supports for heterogeneous catalysis has become a key research topic due to the unique properties of many of these materials (e.g., unlimited availability as renewable agro-resources, nontoxicity, biodegradability, insolubility in most organic solvents,

\footnotetext{
${ }^{a}$ Institut für Organische Chemie, Universität Regensburg, Universitätsstr. 31, 93053 Regensburg, Germany. E-mail: david.diaz@chemie.uni-regensburg.de

${ }^{b}$ Institut Charles Gerhardt Montpellier-UMR 5253 CNRS-UMII-ENSCM-UMI, Matériaux Avancés pour la Catalyse et la Santé, 8 rue de l'École Normale, 34296 Montpellier Cedex 5, France

${ }^{c} I Q A C-C S I C$, Jordi Girona 18-26, 08034 Barcelona, Spain

$\dagger$ Electronic supplementary information (ESI) available: Preliminary optimization experiments, metal loading, leaching study, kinetics, FT-IR spectra, TGA curves, ${ }^{1} \mathrm{H}$ NMR spectra, HPLC chromatograms, and additional experiments. See DOI: 10.1039/c4nj02178a

\$ These authors contributed equally to this work.
}

high binding ability for selected metals, excellent mechanical strength, and the intrinsic presence of different chemical functionalities such as amino, hydroxy, or carboxy groups). ${ }^{3}$ Moreover, the processability and malleability of polysaccharides allows for the preparation of materials with different shapes and morphologies that would be most suitable for a particular application. This property turns out to be even more relevant if we consider the fact that the physical state of several biopolymers plays a significant role in the kinetics of $\mathrm{C}-\mathrm{C}$ bond forming reactions, which have a central importance in modern chemistry and are ultimately a requirement for all life on earth. ${ }^{4-7}$

Among the most abundant polysaccharides, alginates are interesting anionic polymers isolated from brown algae that have been widely applied in drug delivery, ${ }^{8}$ entrapment of bioactive molecules, ${ }^{8,9}$ and as supports in biocatalysis. ${ }^{10-14}$ These biopolymers are linear, unbranched block copolymers of $(1 \rightarrow 4)$-linked $\beta$-D-mannuronate $(\mathrm{M})$ and $\alpha$-L-guluronate $(\mathrm{G})$ monomers that are organized in blocks (i.e., containing $(\mathrm{M})_{m}$, $(\mathrm{G})_{n}$, and $(\mathrm{M}, \mathrm{G})_{x}$ sequences) along the polymer chain (Fig. 1). One of the biggest advantages of alginates is that their solutions (monovalent metal ions form soluble salts) can readily form strong hydrogels with water content $>95 \%$ upon metal exchange with many divalent or multivalent cations, especially $\mathrm{Ca}^{2+}$ (a borderline Lewis acid). ${ }^{15}$ This property is at the core of their natural function as water-storage agents in living organisms, as well as their main applications as immobilization supports and food thickening agents. ${ }^{16}$ The 3D network hydrophilic structure of 


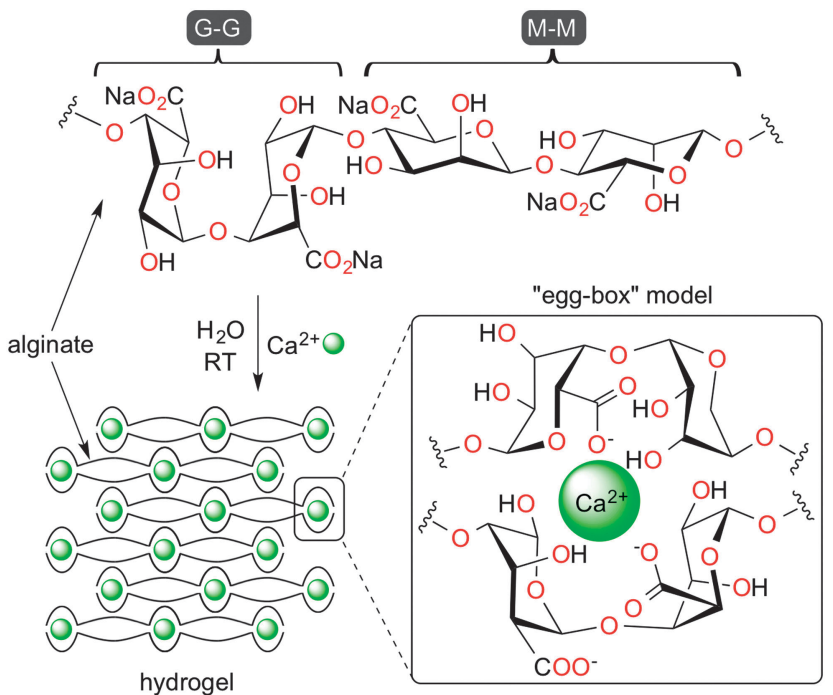

Fig. 1 Structure of the repeating units of sodium alginate $\left(p K_{a}\right.$ of carboxylic groups $\sim 3$ to 4 ), and formation of the hydrogel by coordination of $\mathrm{Ca}^{2+}$ cations between adjacent alginate chains as per the "egg-box" model.

these gels has been described by the so-called "egg-box" model where each calcium atom is coordinated to the carboxylates and hydroxyl groups of four $\mathrm{G}$ monomers from two adjacent chains of the polymers (Fig. 1). ${ }^{17,18}$ The properties of alginate gels are highly influenced by the ratio and sequencing of uronic monomers, ${ }^{19}$ concentration of metal ions, and maturation time. ${ }^{20}$ Importantly, the mechanical strength of the hydrogels can be tuned using monomer ratios, allowing easy handling in different shapes (e.g., beads, tubes, membranes).

The overall potential of metal-alginate complexes in the broad field of non-enzymatic heterogeneous catalysis has only been scarcely explored during the last decade. ${ }^{21}$ In 2005 , Quignard's lab reported the effectiveness of the Pd(TPPTS) complex immobilized on alginate aerogel microspheres as a supported catalyst for the allylic substitution of methyl-allylcarbonate with morpholine. ${ }^{22}$ A few years later, Reddy and his group described the immobilization of $\mathrm{Cu}^{2+}$ ions on alginate gel beads, and their activity towards both the regioselective 1,3-cycloaddition of alkynes and azides, and the oxidative coupling of 2-naphthols and phenols in aqueous medium. ${ }^{23}$ In 2011, Guibal and co-workers described the use of Pd supported on alginate/ionic liquid porous monoliths for the hydrogenation of 4-nitroaniline in the presence of either sodium formate or formic acid as a hydrogen donor. ${ }^{24}$ At the same time, $\mathrm{Fe}^{3+}$-alginate gel beads were successfully used for the oxidative degradation of azo dyes under visible light irradiation. ${ }^{25}$ In 2012, Oudeyer, Dez and co-workers published the catalytic activity of metal or ammonium alginates in the 1,2-addition of silyl nucleophiles to carbonyl compounds. ${ }^{26}$ Quignard's group also reported the synthesis of bimetallic alginate aerogels, obtained upon partial exchange of metal cations with $\mathrm{Pd}^{2+}$, followed by their reduction into Pd-nanoparticles, and their excellent catalytic activity towards the Suzuki-Miyaura cross-coupling reaction. ${ }^{27} \mathrm{Shi}$ and co-workers also reported

the catalytic activity of binary $\mathrm{Cu}-\mathrm{Pd}$-alginate dry beads for hydroxylation of phenol. ${ }^{28}$ Finally, Ag-nanoparticles immobilized on alginate hydrogels have shown good performance in 4-nitrophenol reduction. ${ }^{29-31}$

The objective of the present study was to perform a critical assessment of the potential ability of crosslinked monometalalginates complexes to mediate the Henry (nitroaldol) reaction, one of the most important methods for the formation of C-C bonds. ${ }^{32}$

\section{Results and discussion}

\section{Preparation of $\mathrm{M}^{n+}$-crosslinked alginate hydrogel beads}

A library of different metal-ion crosslinked AHG beads was prepared according to the above-described procedure by using six gelling metals (i.e., $\mathrm{Ca}^{2+}, \mathrm{Cu}^{2+}, \mathrm{Co}^{2+}, \mathrm{Ni}^{2+}, \mathrm{Zn}^{2+}$ and $\left.\mathrm{Fe}^{3+}\right) \cdot{ }^{21,23}$ In all cases, metal chloride salts were used in order to avoid any possible catalytic activity caused by other counter ions $\left(e . g\right.$., $\mathrm{OH}^{-}$if metal hydroxy salts were used) entrapped in the gel matrix. ${ }^{4}$ The set-up used for the preparation of the $\mathrm{M}^{n+}-\mathrm{AHG}$ beads at room temperature is shown in Fig. 2. The viscous alginate aqueous solution $(2 \% \mathrm{w} / \mathrm{v}, \mathrm{ca}$. neutral $\mathrm{pH})$ was added dropwise via a dropping funnel into a beaker containing an aqueous solution $(0.24 \mathrm{M}$, $c a$. neutral $\mathrm{pH}$ ) of the corresponding metal chloride. In order to obtain uniform spherical beads, with an average diameter in the range of 3.6-4.9 mm, the dropping rate (0.5-3 drops per second) and the distance between the tip of the dropping funnel and the surface of the metal-containing solution $(0.5-2.5 \mathrm{~cm})$ was slightly
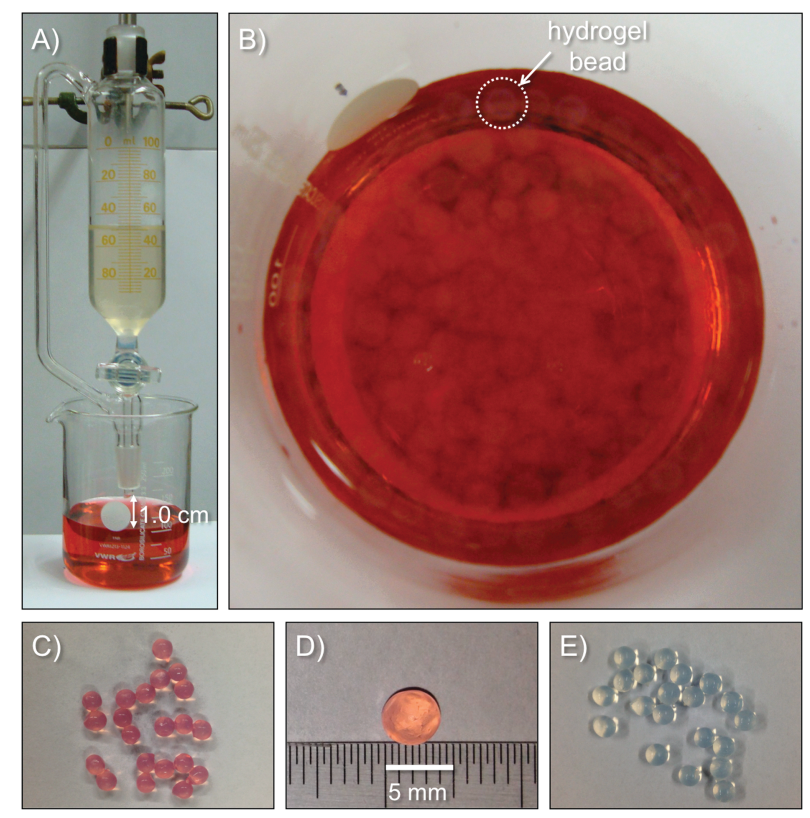

Fig. 2 (A) Set-up used for the preparation of $\mathrm{M}^{n+}$-crosslinked alginate hydrogel beads. The dropping funnel is charged with sodium alginate solution $(2 \% \mathrm{w} / \mathrm{v})$, and the beaker with aqueous solution $(0.24 \mathrm{M})$ of the corresponding metal salt $\left(\mathrm{CoCl}_{2} \cdot 6 \mathrm{H}_{2} \mathrm{O}\right.$ was used here to illustrate the process). (B) Formation of $\mathrm{CO}^{2+}-\mathrm{AHG}$ beads upon coagulation. (C) Isolated $\mathrm{Co}^{2+}-\mathrm{AHG}$ beads. (D) Single $\mathrm{Co}^{2+}-\mathrm{AHG}$ bead $\left(\varnothing=4 \pm 0.2 \mathrm{~mm}\right.$ ). (E) $\mathrm{Ca}^{2+}-$ AHG beads obtained using the same procedure and $\mathrm{CaCl}_{2}$ as metal salt. 
adjusted in each case (Table S2, ESI $\dagger$ ). The obtained beads were matured overnight at room temperature in the gelling solution. After this, the beads were filtered off and washed meticulously with distilled water to remove the excess of metal cations and counter anions. The metal content of the crosslinked hydrogel beads was determined using inductively coupled plasma optical emission spectrometry (ICP-OES). A slight increase in the metal loading with increasing diameter was quantified (Fig. S1, ESI $\dagger$ ).

The FT-IR spectra of the AHG beads showed the expected absorption bands at $1597 \mathrm{~cm}^{-1}$ and $1411 \mathrm{~cm}^{-1}$ (asymmetric and symmetric stretching bands of the carboxylate functional groups, respectively), as well as the typical bands for polysaccharides between 1176 and $1028 \mathrm{~cm}^{-1}$ (C-O, C-C, and C-O-H stretching absorptions). In general, the presence of the divalent/trivalent metal ions in the AHG beads had no major impact on the main vibration modes of the starting sodium alginate. The broad bands observed between 3379 and $3076 \mathrm{~cm}^{-1}$ correspond to the stretching vibrations of the $-\mathrm{OH}$ functional groups (Fig. S4-S6, ESI $\dagger$ ). ${ }^{33}$

TGA thermograms of the alginate-based xerogel materials showed a typical gradual weight loss below $100{ }^{\circ} \mathrm{C}$ which was attributed to the vaporization of the adsorbed moisture and lactonization. ${ }^{34}$ A major and rapid weight loss starting around $200{ }^{\circ} \mathrm{C}$ can be associated with polymer decomposition via decarboxylation, whereas further weight loss above $280{ }^{\circ} \mathrm{C}$ is usually ascribed to the degradation of the alginate backbone and cleavage of numerous hydroxyl groups (Fig. S7, ESI $\dagger$ ). ${ }^{35}$ In agreement with previous studies, a trend of stability in the interval between $200{ }^{\circ} \mathrm{C}$ and $300{ }^{\circ} \mathrm{C}$ could be observed as a function of the metal ion (i.e., stability increases in the order $\mathrm{Fe}^{3+}$ (lowest stability) $<\mathrm{Cu}^{2+}<$ $\left.\mathrm{Na}^{+}<\mathrm{Ni}^{2+} \approx \mathrm{Co}^{2+} \approx \mathrm{Zn}^{2+} \approx \mathrm{Ca}^{2+}\right) .{ }^{36}$

As part of the characterization of materials, SEM images of the xerogels showed porous surfaces with rough-veined structures of high aspect ratios, in contrast to the amorphous structure of commercially powdered sodium alginate (Fig. S10, ESI $\dagger$ ). Although the method used to prepare the xerogels (i.e., air-drying, freezedrying) had a clear impact on the observed morphologies, ${ }^{21}$ the changes were consistent in all samples (Fig. 3). This heterogeneous surface structure of the beads could favor the adsorption of small molecules present in the medium via electrostatic, hydrogen bonding, and/or van der Waals interactions. In addition, the pore size distribution of these materials are affected as a function of the metal ion. ${ }^{36}$ However, the catalytic activity of these materials with different metal ions is likely related to the exact structure of the coordination complexes, which is out of the scope of this manuscript and will constitute the focus of future studies.

\section{Participation of alginate materials in the Henry (nitroaldol) reaction}

The Henry reaction, also called nitroaldol reaction, between nitroalkanes and carbonyl compounds (i.e., aldehydes, ketones) in the presence of an ionic or non-ionic base catalyst is a classical and highly valuable synthetic route to $\beta$-nitroalcohols. ${ }^{32,37}$ From a mechanistic point of view, the selectivity of the reaction with aromatic aldehydes is highly influenced by the electron donating/ accepting nature of the substituents and their ability to favor either the ion-pair or imine mechanism in the presence of a base. ${ }^{32}$
Moreover, enantioselective Henry reactions under dual Lewis acid/ amine catalysis have also been reported. ${ }^{38}$ The practical importance of the nitroaldol reaction in organic synthesis is supported by the fact that $\beta$-nitroalcohols are precursors of the important building blocks (e.g., nitroalkenes, $\alpha$-nitroketones, 1,2-amino alcohols), which are frequently found in numerous pharmaceuticals. ${ }^{39-42}$ Nevertheless, a major shortcoming of this reaction is the formation of several by-products (e.g., polymerizable nitroalkenes formed by dehydration of $\beta$-nitroalcohols, epimerized products, compounds derived either from the Cannizaro or the Nef reaction) that can complicate the isolation of the desired molecules. ${ }^{32}$ Therefore, there is a fundamental interest shown in the development of "green" processes that can selectively yield the $\beta$-nitroalcohols. Among the numerous reports dealing with metal-catalyzed ${ }^{43}$ and organocatalyzed-Henry reactions, ${ }^{44}$ the solid-state condensation of carbonyl compounds with active methylene compounds in the presence of lithium bromide as a mild Lewis acid catalyst has also been described. ${ }^{45}$

Taking everything into consideration, as well as the fact that calcium is one of the cheapest commercially available metals, the fifth most-abundant element in earth's crust, and non-toxic, ${ }^{46,47}$ we decided to investigate the ability of $\mathrm{Ca}^{2+}$-containing alginate biohydrogels to promote the Henry reaction. In preliminary experiments using the model reaction between 4-nitrobenzaldehyde (1a) and nitromethane (2a), we were delighted to observe the gradual formation of the desired $\beta$-nitroalcohol $\mathbf{3 a}$ in the presence of $\mathrm{Ca}^{2+}$-AHG beads under mild conditions (DMSO, room temperature). Initial optimization studies revealed that 10 equivalents of $2 \mathrm{a}$ and one $\mathrm{Ca}^{2+}-\mathrm{AHG}$ bead were necessary to drive the reaction to completion within $24 \mathrm{~h}$ (Table S1, ESI $\dagger$ ). It is worth mentioning that the use of $6 \mathrm{~mol} \%$ of $\mathrm{CaCl}_{2}$ instead of $\mathrm{Ca}^{2+}-\mathrm{AHG}$ did not promote the Henry reaction (i.e., $0 \%$ yield of the desired product was observed after $24 \mathrm{~h}$ ). Although the Henry reaction is simple to carry out, the elucidation of the underlying mechanisms under different conditions is always interesting. In the case of $\mathrm{Ca}^{2+}-\mathrm{AHG}$ a plausible mechanism would involve the carboxylate groups as moderately basic charged ligands and the metallic centers as Lewis acids that activate the nitroalkane towards deprotonation, similarly to the mode of action of copper acetate-bis(oxazolines). ${ }^{48,49}$ Carboxylic acid moieties and/or nitromethane molecules (used in large excess with respect to the aldehyde) could participate in the protonation step of the alcoholate intermediate (Fig. S9, ESI $\dagger$ ). In such dualactivation mechanisms, the embedment of the metal center in the biopolymer matrix could cause a shielding effect preventing the assembly of a highly ordered transition state, ${ }^{49}$ which could explain the observed lack of enantioselectivity.

Table 1 outlines the results of solvent screening for the $\mathrm{Ca}^{2+}$-AHG-promoted Henry reaction. The best results were achieved in DMSO (>99\% conversion, $88 \%$ yield) (entry 1 ), where the control experiment in the absence of $\mathrm{Ca}^{2+}$-AHG showed no conversion. On the other hand, only $16 \%$ yield could be achieved in $\mathrm{H}_{2} \mathrm{O}$ (entry 3), although the addition of a phase transfer additive such as TBAB increased the yield by almost three times (entry 4). Nevertheless, in sharp contrast to DMSO, the background reaction (control in the absence of the catalyst) in the $\mathrm{H}_{2} \mathrm{O}-\mathrm{TBAB}$ system was $c a$. $6 \%$. Low yields were observed in EtOH (entry 5), whereas only traces or no product could be detected when the reaction was carried out in 

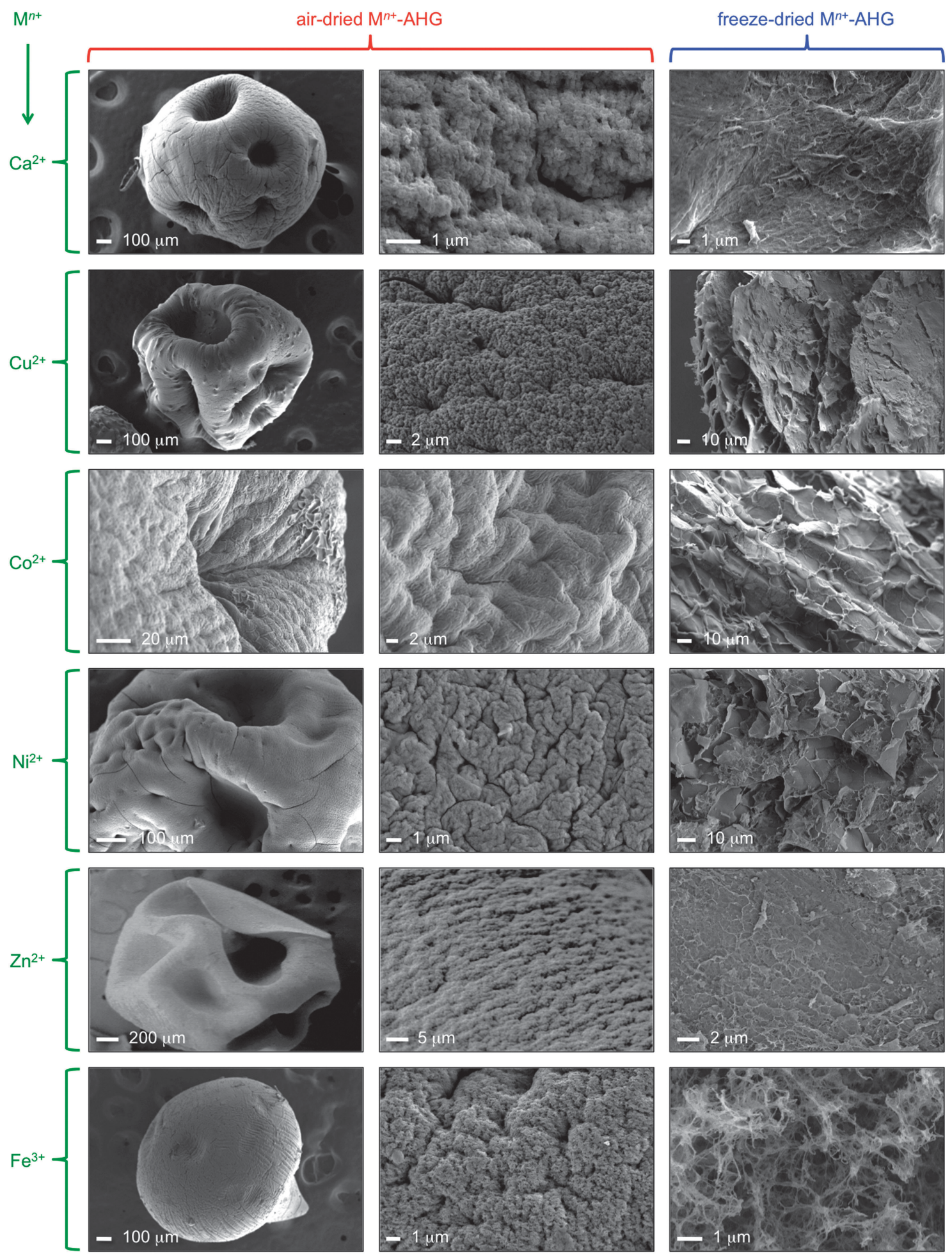

Fig. 3 SEM images of different $M^{n+}$-alginate-based xerogel materials. Pictures in the same row correspond to the same metal (left). Xerogels were obtained after either air-drying (left and middle columns) or freeze-drying (right column) the corresponding $\mathrm{M}^{n+}-\mathrm{AHG}$ beads.

$\mathrm{CH}_{3} \mathrm{CN}$, THF, $\mathrm{CH}_{2} \mathrm{Cl}_{2}$ or toluene (entries 6 and 7). Interestingly, the presence of one of these solvents in the reaction was tolerated well if combined with DMSO in a specific ratio (i.e., DMSO/toluene $3: 1(\mathrm{v} / \mathrm{v})$, Table S7, ESI $\dagger$ ) (entry 2). Unfortunately, unambiguous correlations between solvent properties and reaction kinetics could not be drawn at this point (Table S10, ESI $\dagger$ ), suggesting the existence of a complex relationship between these parameters. In terms of kinetics, the rate of the $\mathrm{Ca}^{2+}-\mathrm{AHG}$ bead-catalyzed Henry reaction (Fig. 4) was found to be slower than standard base catalysts such as $\mathrm{Et}_{3} \mathrm{~N}$, but was comparable to other metal-catalyzed 
Table 1 Solvent screening study of $\mathrm{Ca}^{2+}$-AHG-promoted Henry reaction ${ }^{2}$

\begin{tabular}{|c|c|c|}
\hline $\mathrm{O}_{2} \mathrm{~N}$ & $\begin{array}{r}\mathrm{CH}_{3} \mathrm{NO}_{2} \\
\mathbf{2 a} \\
\end{array}$ & $\stackrel{\mathrm{OH}}{\mathrm{NO}_{2}}$ \\
\hline Entry & Solvent & Yield $\mathbf{3} \mathbf{a}^{b}(\%)$ \\
\hline 1 & DMSO & $88\left(0^{c}\right)$ \\
\hline 2 & DMSO-toluene ${ }^{d}$ & 83 \\
\hline 3 & $\mathrm{H}_{2} \mathrm{O}$ & $16\left(<2^{c}\right)$ \\
\hline 4 & $\mathrm{H}_{2} \mathrm{O}-\mathrm{TBAB}^{e}$ & $44\left(6^{c}\right)$ \\
\hline 5 & EtOH & 9 \\
\hline 6 & $\mathrm{CH}_{3} \mathrm{CN}, \mathrm{THF}$ & $<2$ \\
\hline 7 & $\mathrm{CH}_{2} \mathrm{Cl}_{2}$, toluene & 0 \\
\hline
\end{tabular}

${ }^{a}$ Reaction conditions: 4-nitrobenzaldehyde (1a, $\left.0.1 \mathrm{mmol}\right)$, nitromethane (2a, $1.0 \mathrm{mmol}), \mathrm{Ca}^{2+}-\mathrm{AHG}$ bead ( 1 bead, $c a .5 \mathrm{~mol} \%$ of metal with respect to $1 \mathrm{a})$, solvent $(0.5 \mathrm{~mL})$, room temperature, $24 \mathrm{~h} .{ }^{b}$ Determined using ${ }^{1} \mathrm{H}$ NMR analysis of the crude product $(9.2 \mu \mathrm{L}$ of DMA was used as internal standard). The reported values correspond to the average values of at least two independent experiments (STDV $= \pm 2$ ). ${ }^{c}$ Control experiment made in the absence of $\mathrm{Ca}^{2+}-\mathrm{AHG}$ bead. ${ }^{d} \mathrm{DMSO} /$ toluene ratio $=3: 1(\mathrm{v} / \mathrm{v}) .{ }^{e}$ Tetra- $n$-butylammonium bromide $(0.04 \mathrm{mmol})$.

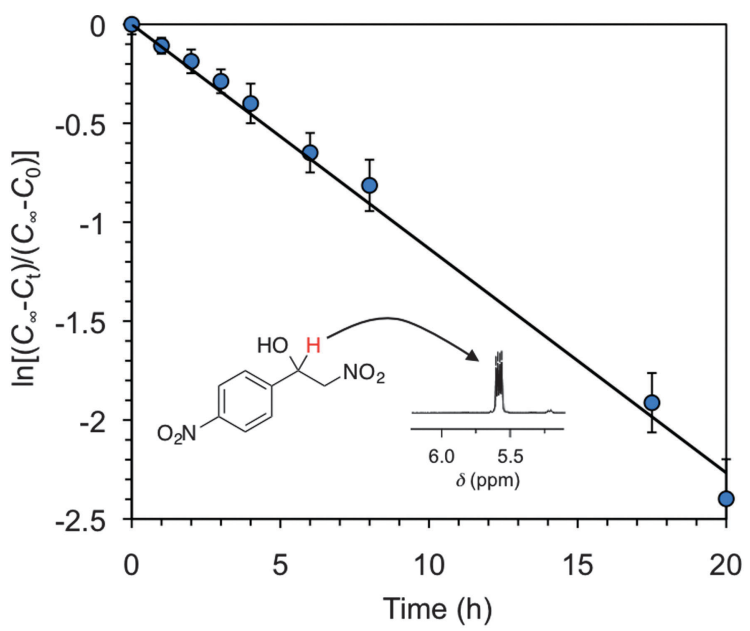

Fig. 4 Kinetics analysis of the $\mathrm{Ca}^{2+}-\mathrm{AHG}$-promoted Henry reaction between 4-nitrobenzaldehyde (1a) and nitromethane (2a) as described in Table 1. Each data point represents the average of at least two independent measurements. $C_{\infty}=$ final concentration at infinite time; $C_{t}=$ concentration at given time $t ; C_{0}=$ initial concentration at $t=$ zero time. Apparent rate constant, $k=0.113 \pm 0.04 \mathrm{~h}^{-1}$. Inset: characteristic signal of the benzylic proton in the ${ }^{1} \mathrm{H}$ NMR spectrum of the $\beta$-nitroalcohol product.

reactions (Table S9, ESI $\dagger$ ). At this point, we hypothesized that lowmolecular-weight calcium alkyl carboxylates may also mediate the formation of $\beta$-nitroalcohols in good yields under the studied conditions. Indeed, when the model reaction between $\mathbf{1 a}$ and $\mathbf{2 a}$ in DMSO was carried out in the presence of soluble calcium 2-ethylhexanoate ( $c a .2 .1 \mathrm{~mol} \%$ ), a well-established catalyst for homogeneous industrial polymerizations, the desired $\beta$-nitroalcohol 3a was formed in 90\% yield within $3 \mathrm{~h}$ (Table S3, ESI $\dagger$ ). Despite the higher catalytic activity of calcium 2-ethylhexanoate in comparison to $\mathrm{Ca}^{2+}$-AHG beads, heterogeneity and recyclability are sacrificed in the former case. In addition, and in agreement with the
Table 2 Influence of the metal ion in the $\mathrm{M}^{n+}$-AHG-promoted Henry reaction $^{a}$

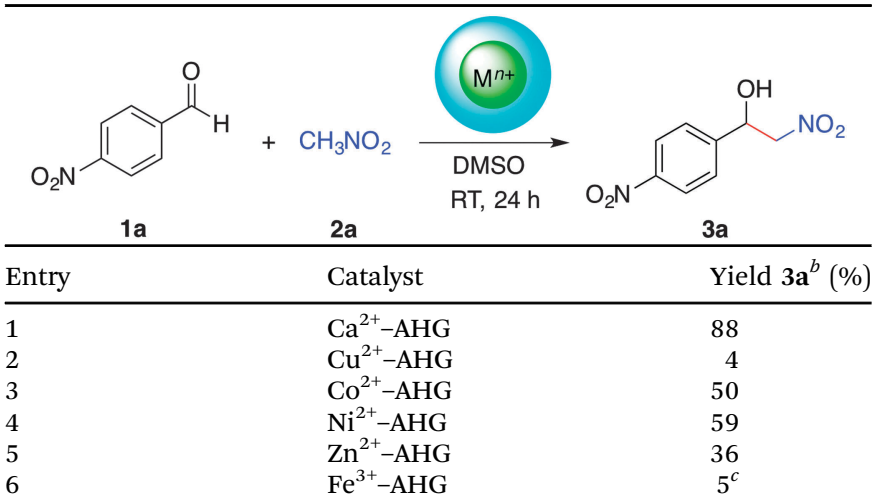

${ }^{a}$ Reaction conditions: 4-nitrobenzaldehyde (1a, $0.1 \mathrm{mmol}$ ), nitromethane (2a, $1.0 \mathrm{mmol}$ ), $\mathrm{M}^{n+}$-AHG ( 1 bead, $4 \pm 1 \mathrm{~mol} \%$ of metal with respect to 1a), DSMO $(0.5 \mathrm{~mL})$, room temperature, $24 \mathrm{~h} .{ }^{b}$ Determined using ${ }^{1} \mathrm{H}$ NMR analysis of the crude product $(9.2 \mu \mathrm{L}$ of DMA was used as the internal standard). Reported values correspond to the average values of at least two independent experiments $(\mathrm{STDV}= \pm 2) .{ }^{c} \mathrm{Fe}^{3+}-\mathrm{AHG}$ bead was not stable and underwent severe fragmentation during the reaction.

corresponding MSDS, both calcium 2-ethylhexanoate and its dissociation product (i.e., 2-ethylhexanoic acid) are known to be irritants to the eyes, respiratory system, and skin.

Equally importantly from a practical perspective, the scale-up of the target model reaction from $0.1 \mathrm{mmol}$ to $7.5 \mathrm{mmol}(1.13 \mathrm{~g})$ of $1 \mathrm{a}$ also lead satisfactorily to the formation of 3a with an isolated yield of $82 \%$. With these results in hand, we chose the model reaction between 1a and 2a in DMSO for further investigations.

Considering the differences in the Lewis acid character of each metal, as well as the fact that both morphology and porosity of the hydrogel networks are different depending on the metal center, ${ }^{50}$ we expected to observe a major effect of the metal nature on the kinetics of the $\mathrm{M}^{n+}$-AHG bead-catalyzed Henry reaction. ${ }^{2,3}$ Table 2 summarizes the results of this investigation using ca. $4 \pm 1 \mathrm{~mol} \%$ of the metal catalyst with respect to the aldehyde (ESI $\dagger$ ). The best result was achieved with $\mathrm{Ca}^{2+}-$ AHG beads ( $88 \%$ yield, Table 2 , entry 1 ), although modest yields between 50 and $60 \%$ could also be obtained using $\mathrm{Co}^{2+}$-AHG (entry 3 ) and $\mathrm{Ni}^{2+}$-AHG beads (entry 4 ). $\mathrm{Zn}^{2+}$ AHG beads afforded the corresponding $\beta$-nitroalcohol 3a, albeit in lower yields (entry 5), whereas the use of $\mathrm{Cu}^{2+}-\mathrm{AHG}$ and $\mathrm{Fe}^{3+}-\mathrm{AHG}$ provided the desired product in very poor yields (entries 2 and 6 respectively). It is noteworthy that all hydrogel beads, except $\mathrm{Fe}^{3+}-\mathrm{AHG}$, remained physically stable under the reaction conditions without visual deterioration. It should be noted, however, that further detailed studies using electron microscopy are necessary in order to precisely evaluate any morphological change of the hydrogels caused by their immersion into different solvents. Although we have not carried out experiments in order to improve the lower yields, it is expected that extension of the reaction time and/or slight increase of the temperature could increase them. ${ }^{7}$

On the other hand, negligible enantioselectivities (ee $\leq 5 \%$ ) were detected in all the experiments (ESI $\dagger$ ), indicating that the reaction is not sensitive under the reported conditions to 
the primary chirality of the polysaccharide backbone or to a possible secondary chirality due to the formation of a helical conformation upon metal coordination. In general, the lack of enantioselectivity has been also reported for other catalysts and biocatalysts bearing intrinsic chirality., ${ }^{4,5,51-53}$ Moreover, we found that the use of DMSO as a solvent could also frustrate, at least to a certain extent, the formation of highly ordered transition states necessary to induce stereoselectivity in the Henry reaction. We corroborated this statement in our run of the model reaction in the presence of 2,2-bis((4S)-(-)-4isopropyloxazoline)propane as the chiral ligand in combination with $\mathrm{Cu}(\mathrm{OAc})_{2} \cdot \mathrm{H}_{2} \mathrm{O}$ (the ligand was synthesized as previously reported and displayed the expected spectroscopic data ${ }^{48}$ ). In agreement with previous observations, the bisoxazoline complex showed a significant enantioselectivity ( $c a .65 \%$ ee) in $\mathrm{MeOH},{ }^{49}$ whereas only the racemic product could be isolated in DMSO.

During our previous research regarding the intrinsic catalytic activity of biopolymers and proteins, we have established that the morphology and/or physical state of the biocatalyst plays an important role in the kinetics of aldol-like reactions under heterogeneous or semi-heterogeneous conditions. ${ }^{2,3}$ Therefore, we decided to carry out here a comparative evaluation of the model reaction between $1 \mathrm{a}$ and 2a using different forms of the catalyst in DMSO at room temperature (Table 3). In sharp contrast to the hydrogel form of the catalyst (entry 1), the xerogels obtained either by freeze-drying (entry 2) or air-drying (entry 3 ) the corresponding $\mathrm{Ca}^{2+}-\mathrm{AHG}$ beads afforded the desired product in very poor yields $(<5 \%)$ (Tables S5 and S6, ESI $\dagger$ ). Considering the measured water content of the hydrogel beads (i.e., $434 \mu \mathrm{L}$ per bead), we carried out another control experiment using the freeze-dried form of the catalyst in combination with the amount of water held in the hydrogel form (entry 4). However, only a slight improvement could be achieved

Table 3 Influence of the physical state of $\mathrm{M}^{n+}-\mathrm{AHG}$ in the catalyzed Henry reaction ${ }^{a}$

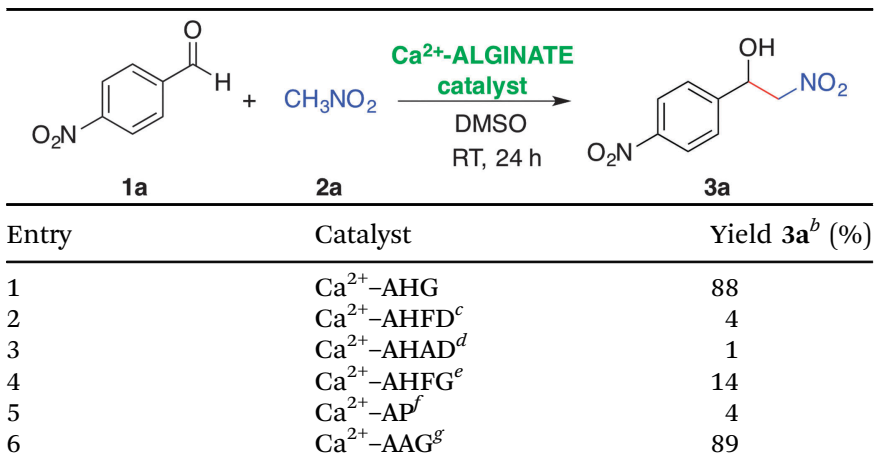

${ }^{a}$ Reaction conditions: 4-nitrobenzaldehyde (1a, $0.1 \mathrm{mmol}$ ), nitromethane (2a, $1.0 \mathrm{mmol}$ ), catalyst ( $1 \mathrm{bead}, \mathrm{ca} .5 \mathrm{~mol} \%$ of metal with respect to 1a), DMSO $(0.5 \mathrm{~mL})$, room temperature, $24 \mathrm{~h} .{ }^{b}$ Determined using ${ }^{1} \mathrm{H}$ NMR analysis of the crude product $(9.2 \mu \mathrm{L}$ of DMA was used as the internal standard). Reported values correspond to the average values of at least two independent experiments (STDV $= \pm 2) .{ }^{c}$ Freeze-dried form of the alginate hydrogel bead. ${ }^{d}$ Air-dried form of the alginate hydrogel bead. The average volume of the obtained xerogel beads was ca. $3 \%$ of the average volume of the hydrogel beads. ${ }^{e}$ Freeze-dried form of the alginate hydrogel bead and $434 \mu \mathrm{L}$ of $\mathrm{H}_{2} \mathrm{O} .{ }^{f}$ Commercial powder calcium alginate $(1 \mathrm{mg}) \cdot{ }^{g}$ Alginate aerogel bead prepared from the corresponding hydrogel bead as described in the Experimental section. (i.e., 14\% yield of the desired product). This slight positive effect could be also observed upon using commercial available sodium alginate powder $\left(\mathrm{Na}^{+}-\mathrm{AP}\right)$ as the catalyst. Specifically, when the model reaction was run using $0.4 \mathrm{mg}$ of $\mathrm{Na}^{+}-\mathrm{AP}(\mathrm{ca} .2 .1 \mathrm{~mol} \%)^{54}$ in DMSO, the desired product was formed in only $6 \%$ yield. However, the addition of $434 \mu \mathrm{L}$ of $\mathrm{H}_{2} \mathrm{O}$ to the reaction containing $\mathrm{Na}^{+}$-AP increased the product yield up to $13 \%$. Herein, the control reaction performed in DMSO $+\mathrm{H}_{2} \mathrm{O}(434 \mu \mathrm{L})$ in the absence of $\mathrm{Na}^{+}$-AP provided null conversion. Considering the amorphous microstructure of $\mathrm{Na}^{+}-\mathrm{AP}$ (Fig. S10, ESI $\dagger$ ), the modest positive effect caused by the addition of $\mathrm{H}_{2} \mathrm{O}$ could also be attributed to its potential role as a plastifier of polysaccharides, increasing the accessibility to amorphous domains. ${ }^{22}$ Moreover, the direct use of commercial amorphous calcium alginate powder resulted in very poor yields (entry 5 ).

In general, the afore-described results suggest that the characteristics of the hydrogel also play an important role in the Henry reaction under the described conditions. In general, catalysts with sponge-like and rough-veined microstructures showed higher activities than those with closed and agglomerated surfaces where the molecular adsorption is disfavored (Fig. 3 and Fig. S9, ESI $\dagger$ ). Last but not least, the use of the mesoporous aerogel form of the catalyst (Table 3, entry 6), prepared by supercritical $\mathrm{CO}_{2}$ drying (see Experimental section), provided only slightly superior yields and kinetics (Fig. S3 and Table S8, ESI $\dagger$ ) in comparison to the $\mathrm{Ca}^{2+}-\mathrm{AHG}$ beads of lower surface area, albeit without significant enantioselectivity (ee $\approx 6 \%$ ). Overall, these results suggest the existence of a complex reaction mechanism involving both diffusion-controlled processes and surface reactivity. Evidence of surface reactivity instead of nanoreactor $^{55-58}$ activity was also obtained from further experiments where the reactive contact surface area of the hydrogel beads was modified (Fig. S8, ESI $\dagger$ ).

At this point we explored the substrate scope of the $\mathrm{Ca}^{2+}$ AHG-promoted Henry reaction in DMSO at room temperature (Table 4). In general, aromatic aldehydes with moderate or strong electron-withdrawing groups were converted selectively into the corresponding $\beta$-nitroalcohols in very good yields (entries 1-6), and without a dramatic influence of the position of the substituents in $\mathbf{1}$ (entries 1-3). Aromatic aldehydes with weak electron-withdrawing groups could be converted into the desired products, albeit with lower yields (entries 8-10). However, both benzaldehyde and 4-methylbenzaldehyde were poorly converted (entries 7 and 11). Remarkably, heteroaromatic systems such as 2-pyridinecarboxaldehyde also led to $50 \%$ yield (entry 12 ). In contrast, aliphatic aldehydes could not be converted into the desired product. On the other hand, similar results were obtained when using either nitromethane $\left(2, \mathrm{p} K_{\mathrm{a}}=10.2\right)^{59}$ or nitroethane $\left(4, \mathrm{p} K_{\mathrm{a}}=8.6\right)^{59}$ as nucleophiles (entries $2,6,10$ ). Therefore, neither the size nor the $\mathrm{p} K_{\mathrm{a}}$ of the carbanion plays a major role in determining the outcome of the reaction. Although the diastereoselectivity (anti/syn ratio) observed in the $\mathrm{Ca}^{2+}$-AHG-catalyzed reactions with 4 was minor, an interesting trend towards the syn isomer was noticed, which was in contrast to the outcome of the control experiment where the anti isomer was favored. 
Table 4 Substrate scope of the $\mathrm{Ca}^{2+}-\mathrm{AHG}$-catalyzed Henry reaction in $\mathrm{DMSO}^{\mathrm{a}}$

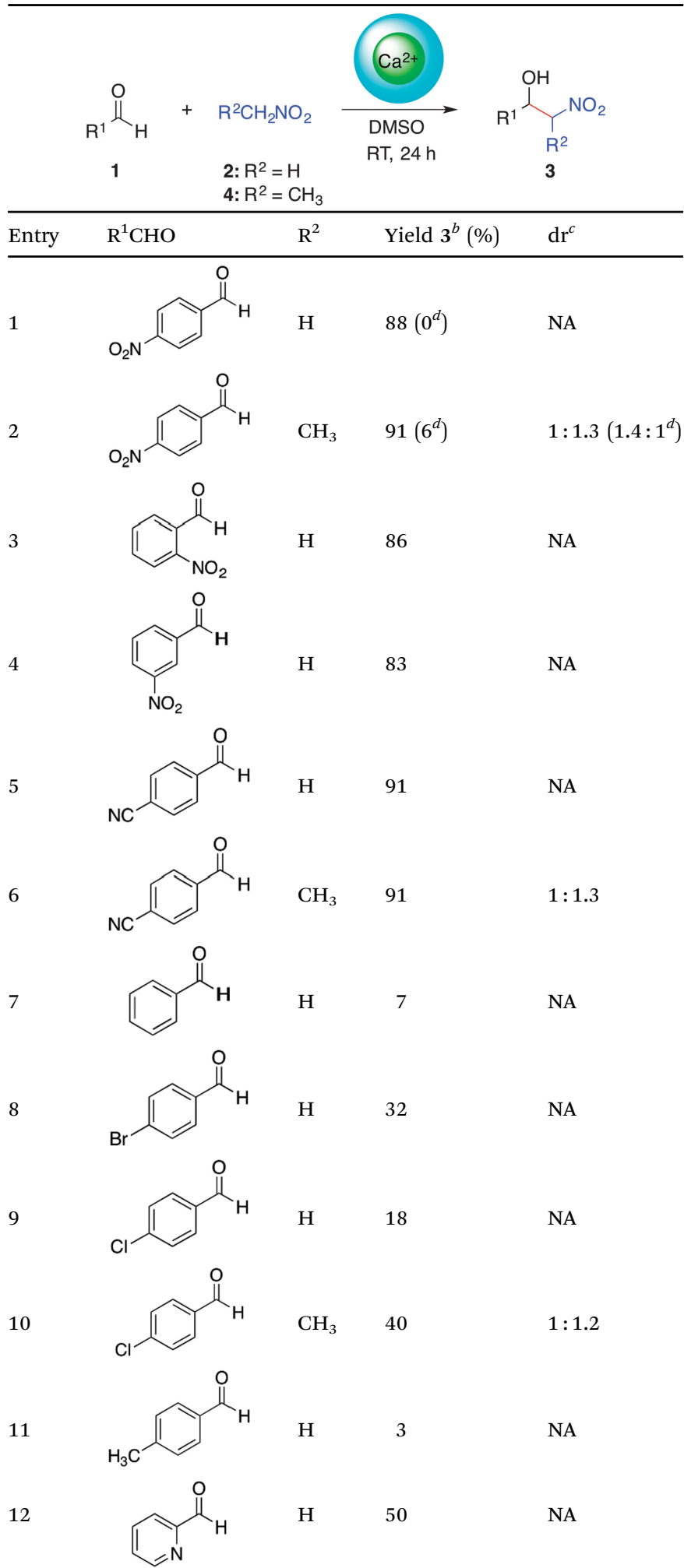

${ }^{a}$ Reaction conditions: aldehyde (1, $\left.0.1 \mathrm{mmol}\right)$, nitroalkane $(2,1.0 \mathrm{mmol})$, DMSO $(0.5 \mathrm{~mL}), \mathrm{Ca}^{2+}$-AHG $(1 \mathrm{bead}, \mathrm{ca} .5 \mathrm{~mol} \%$ of metal with respect to aldehyde), room temperature, $24 \mathrm{~h} .{ }^{b}$ Determined using ${ }^{1} \mathrm{H}$ NMR analysis of the crude product. The reported values correspond to the average values of at least two independent experiments (STDV $= \pm 3$ ). ${ }^{c}$ Diastereomeric ratio (anti/syn) determined by ${ }^{1} \mathrm{H}$ NMR analysis. NA $=$ Not applicable. ${ }^{d}$ Control experiment performed in the absence of $\mathrm{Ca}^{2+}-\mathrm{AHG}$.
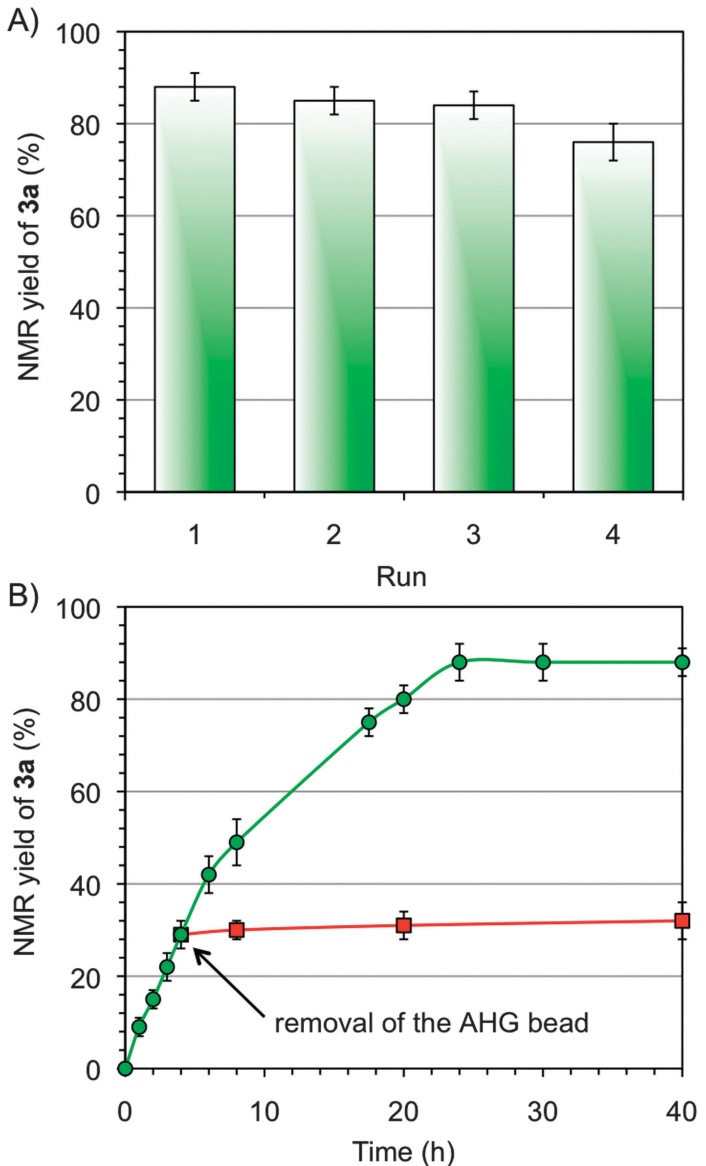

Fig. 5 (A) Typical recycling experiment for the $\mathrm{Ca}^{2+}-\mathrm{AHG}$-promoted Henry reaction. Reaction conditions: 4-nitrobenzaldehyde (15.1 mg, $0.1 \mathrm{mmol})$, nitromethane $(54 \mu \mathrm{L}, 1.0 \mathrm{mmol}), \mathrm{DMSO}(0.5 \mathrm{~mL}), \mathrm{Ca}^{2+}-\mathrm{AHG}$ (1 bead), room temperature, 24 h. (B) Control experiment showing the stagnation point of the reaction (green circles) upon removal of the catalyst (red squares).

Regarding recyclability, $\mathrm{Ca}^{2+}$-AHG beads could be reused at least three times without significant loss of activity. However, a gradual deactivation was detected after the 3rd cycle (Fig. 5A). In agreement with previous reports, blocking of the catalyst surface by aldehyde molecules ${ }^{26}$ poisoning of the polysaccharide backbone, ${ }^{27}$ or textural instability ${ }^{22}$ under the reaction conditions could be responsible for the observed activity loss.

Additional control experiments highlighted the heterogeneous nature of the process catalyzed by the $\mathrm{Ca}^{2+}$-biohydrogels. For example, one $\mathrm{Ca}^{2+}$-AHG bead was matured for $24 \mathrm{~h}$ in DMSO without substrates, filtered off, and reused in a new mixture including the substrates of the model reaction. In this case the yields were almost identical to those obtained using freshly prepared $\mathrm{Ca}^{2+}$-AHG beads. A negligible catalytic effect caused by possible leaching of metal ions was demonstrated by nearly null catalytic activity ( $\leq 2 \%$ yield) of (1) the maturing solution obtained from the previous experiment or after a catalytic cycle, and (2) a stock solution containing the maximum theoretically possible leaching for a given bead (this solution was used as a potential catalyst instead of the corresponding $\mathrm{M}^{n+}$-AHG bead - i.e., $7.14 \mathrm{mM} \mathrm{CoCl}{ }_{2} \cdot 6 \mathrm{H}_{2} \mathrm{O}$ solution for $\mathrm{M}=\mathrm{Co}-$ Table S3, ESI $\dagger$ ). 
Table 5 Lipase-catalyzed kinetic resolution of $\beta$-nitroalcohols ${ }^{a}$

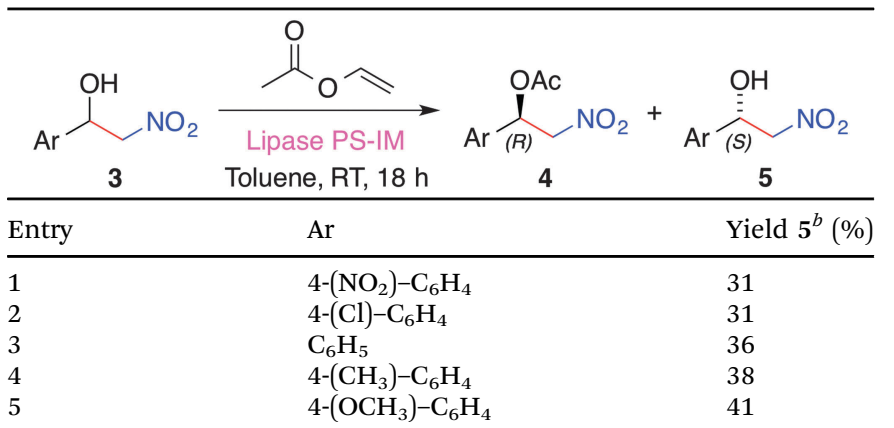

${ }^{a}$ Reaction conditions: $\beta$-nitroalcohol $(3,0.1 \mathrm{mmol})$, vinyl acetate $(46 \mu \mathrm{L}$, $0.5 \mathrm{mmol})$, lipase PS-IM $(50 \mathrm{mg})$, toluene $(0.5 \mathrm{~mL})$, room temperature, 18 h. ${ }^{b}$ Determined using NMR analysis. HPLC optical purity $>95 \%$.

As expected, stagnation of the reaction after removal of the catalyst was observed (Fig. 5B).

In order to access optical pure $\beta$-nitroalcohols a combination of the $\mathrm{Ca}^{2+}$-alginate catalysis with a lipase PS-catalyzed acyl kinetic resolution (KR) could be carried out. ${ }^{60}$ Thus, the synthesized racemic $\beta$-nitroalcohols could be subjected to a KR in the presence of vinyl acetate (VA) as an acyl donor and immobilized Amano lipase PS in toluene at room temperature (Table 5). In reasonable agreement with previous studies, ${ }^{61}$ selected $\beta$-nitroalcohols were isolated in good yields ( $c$ a. 30-40\%) and ee values (>95\%) after the KR. A rigorous "one-pot" process was not feasible because (1) the solvents required for achieving good yields in each step were incompatible (e.g., the lipase-catalyzed KR was not effective in DMSO, whereas the $\mathrm{Ca}^{2+}$-alginate catalysis did not proceed in toluene, moreover, attempts to use DMSO-toluene mixtures led to unsatisfactory results), and (2) a control experiment carried out by incubation of alginate beads, nitromethane and VA showed the consumption of the acyl donor. Nevertheless, we found that VA and lipase PS-IM could be added to the reaction flask after the completion of the first step. Further shaking (not stirring!) at room temperature for $18 \mathrm{~h}$ allowed for the KR step to take place in the same flask (e.g., (S)-2-nitro-1-(4-nitrophenyl)ethan-1-ol could be obtained in $40 \%$ using this procedure).

\section{Conclusions}

In conclusion, $\mathrm{Ca}^{2+}$-AHG beads are able to promote the Henry (nitroaldol) reaction between electron-deficient aromatic aldehydes and nitroalkanes to form $\beta$-nitroalcohols in reasonably good yields under mild conditions. Neither $\mathrm{CaCl}_{2}$ nor amorphous calcium alginate powder were effective as catalysts. Therefore, we have revealed an interesting synergism between the metal ion and the hydrogel network towards the catalysis of $\mathrm{C}-\mathrm{C}$ bond forming reactions. Moreover, the Henry reaction proceeded to a different extent in both non-toxic organic solvents (DMSO) ${ }^{62}$ and aqueous media $\left(\mathrm{H}_{2} \mathrm{O}-\mathrm{TBAB}\right)$ at room temperature within $24 \mathrm{~h}$. The study highlighted that biohydrogels prepared using other metal ions (i.e., $\mathrm{Co}^{2+}$, $\mathrm{Ni}^{2+}, \mathrm{Zn}^{2+}$ ) were also active (ca. 40-60\% yields for the model reaction between 4-nitrobenzaldehyde and nitromethane), although their performance was significantly worse in comparison to $\mathrm{Ca}^{2+}$-AHG
( $88 \%$ yield). Interestingly, when nitroethane was used as nucleophile the $s y n$-isomer of the reaction product was slightly favoured $(1: 1.3)$. Furthermore, the above-mentioned model reaction could be scaled-up $(1 \mathrm{~g})$ providing the corresponding $\beta$-nitroalcohol in a good isolated yield (82\%), and the catalyst could be recycled for at least three consecutive runs without major loss of activity. We believe that the use of biocompatible and robust biopolymer-based materials bearing intrinsic surface functionalities, which can be easily mass-produced at a low cost and in a reproducible manner, may contribute to the development of "greener" catalysts in the future.

\section{Experimental section}

\section{Materials and methods}

${ }^{1} \mathrm{H}$ NMR spectra were recorded at $25{ }^{\circ} \mathrm{C}$ on a Bruker Avance 300 spectrometer. Chemical shifts are denoted in $\delta(\mathrm{ppm})$ relative to tetramethylsilane (TMS $\delta=0$ ) as an internal standard or relative to residual solvent peaks. Samples were analyzed using chiral-phase HPLC using a Varian 920-LC Liquid Chromatograph and a column Phenomenex Lux Cellulose-1, $4.6 \times 250 \mathrm{~mm}, 5 \mu \mathrm{m}$. TLC was facilitated by the use of the following stains in addition to UV light $(254 \mathrm{~nm})$ with fluorescence-indicating plates (aluminium sheet precoated with silica gel 60 F254, Merck): phosphomolybdic acid, vanillin, iodine. The metal content of the hydrogel beads was determined using inductively coupled plasma optical emission spectrometry (ICP-OES) with a Spectro Analytical Instruments ICP Modula EOP. IR spectra were recorded using a Bio-Rad FT-IR Excalibur FTS 3000 equipped with a Diamond ATR (attenuated total reflection) accessory (Golden Gate). The morphology of the xerogels was observed on a Carl Zeiss Merlin field-emission scanning electron microscope (FE-SEM, resolution $0.8 \mathrm{~nm}$ ) equipped with a digital camera and operating at $5 \mathrm{kV}$ (accelerating voltage) and $10 \mu \mathrm{A}$ (emission current). Xerogel specimens were prepared using the freeze-drying (FD) method from the corresponding hydrogels. The resulting material was placed on top of a tin plate and shielded by Pt ( $40 \mathrm{~mA}$ during $30 \mathrm{~s}$; film thickness $\approx 5 \mathrm{~nm}$ ). SEM images were obtained in other cases using a Zeiss DSM 950 scanning electron microscope operated at $10 \mathrm{kV}$ after sputtering the samples with $\mathrm{Au}$ using a SCD 040 from Balzers Union. Thermal gravimetric analysis (TGA) of the samples was conducted with a Mettler Toledo Thermobalance TG50 apparatus. The samples were combusted under an argon flow $(200 \mathrm{~mL})$ in a heating range from 25 to $350{ }^{\circ} \mathrm{C}$ at a heating rate of $10^{\circ} \mathrm{C} \mathrm{min}{ }^{-1}$. Analytical-grade solvents and commercially available reagents were purchased from commercial suppliers and were used as received, unless otherwise noted. Aldehydes were purchased from TCI Europe (ESI†). Sodium alginate (cat. no. A2158-100G; batch no. 106K0113; CAS 9005-38-3; isolated from brown algae; viscosity $100-300 \mathrm{cps}$ for a $2 \%$ aqueous solution at $25{ }^{\circ} \mathrm{C}$ ), calcium alginate from brown algae (cat. no. 21054-50G; batch no. BCBM8132V; CAS 9005-35-0), and Amano lipase PS-IM (immobilized on diatomaceous earth, cat. no. 709603-10G) were purchased from Sigma-Aldrich and used without further 
purification. Pure $\mathrm{H}_{2} \mathrm{O}$ (milliQ) was used in all experiments including water.

\section{Procedures}

Typical procedure for the preparation of metal-crosslinked alginate hydrogel beads. $50 \mathrm{~mL}$ of a solution of sodium alginate in milliQ water $(2 \% \mathrm{w} / \mathrm{v})$ was added dropwise at room temperature to $100 \mathrm{~mL}$ of aqueous metal chloride solution $(0.24 \mathrm{M})$ via a dropping funnel (diameter of the tip $=4.0 \mathrm{~mm}$ ). The volumetric ratio between the sodium alginate solution and the metal chloride solution (1:2) was kept constant in each case. After complete addition of the alginate solution, the beads were cured in the metal stock solution overnight at room temperature. Finally, the obtained alginate hydrogel (AHG) beads were filtered over a Buchner funnel and washed with milliQ water until no metal residues could be detected in the washing solution. Different compounds for metal complexation were used for qualitative metal detection (Table S2 and Fig. S2, ESI $\dagger$ ).

General procedure for the preparation of $\mathrm{Ca}^{2+}$-crosslinked alginate aerogel beads. $\mathrm{Ca}^{2+}$-crosslinked alginate hydrogel beads were first dehydrated in a series of successive ethanol-water baths of increasing alcohol concentration (i.e., 10, 30, 50, 70, 90, and $100 \%$ ) for $15 \mathrm{~min}$ each. The so-obtained alcogel beads were then dried under supercritical $\mathrm{CO}_{2}$ conditions (slightly beyond 73 bar and $31{ }^{\circ} \mathrm{C}$ ) using a Polaron 3100 apparatus affording the corresponding aerogel beads.

Representative procedure for the metal AHG-promoted nitroaldol reaction. To a mixture of 4-nitrobenzaldehyde (0.1 mmol, $15.1 \mathrm{mg})$, nitromethane ( $1 \mathrm{mmol}, 54 \mu \mathrm{L}, 10$ equiv.) and DMSO $(0.5 \mathrm{~mL})$ in a screw cap vial $(4 \mathrm{~mL}), 1$ metal AHG bead was added to initiate the reaction. The resulting reaction mixture was gently stirred for $24 \mathrm{~h}$ at room temperature. After completion, EtOAc $(1 \mathrm{~mL})$ was added. The diluted supernatant solution was removed and the remaining catalyst was washed with EtOAc $(3 \times 1 \mathrm{~mL})$ for $5 \mathrm{~min}$ during each cycle. The combined organic phases were washed with $\mathrm{H}_{2} \mathrm{O}(2 \times 5 \mathrm{~mL})$ and brine $(5 \mathrm{~mL})$, dried over anhydrous $\mathrm{Na}_{2} \mathrm{SO}_{4}$, filtered and evaporated under reduced pressure to obtain the crude product. To determine the NMR yield, the crude product was dissolved in $\mathrm{CDCl}_{3}(1 \mathrm{~mL})$ and diphenylmethane $(0.1 \mathrm{mmol}, 16.7 \mu \mathrm{L})$ or dimethyl acetamide $(0.1 \mathrm{mmol}, 9.2 \mu \mathrm{L})$ were added as internal standards. Random isolation of desired products showed only small differences between the isolated yield and the NMR yield (i.e., ca. 5\%).

Typical recycling experiment for the $\mathrm{Ca}^{2+}-\mathrm{AHG}$-promoted Henry (nitroaldol) reaction. After quenching the reaction as described above, the catalyst was washed with further DMSO $(0.5 \mathrm{~mL})$ to remove any possible EtOAc residue. The hydrogel beads were subsequently added to a new mixture of substrates in DMSO. This procedure was repeated for all further cycles. The work-up and determination of the yield was determined as described in the representative procedure for the $\mathrm{M}^{n+}$-AHG-promoted Henry reaction.

Representative procedure for the lipase-catalyzed kinetic resolution of racemic mixtures. Amano lipase PS-IM (50 mg) was added in one portion to a solution of the corresponding $\beta$-nitroalcohol $(0.1 \mathrm{mmol})$ in toluene $(0.5 \mathrm{~mL})$ at room temperature. The reaction mixture was shaken at $200 \mathrm{rpm}$ for $18 \mathrm{~h}$ at room temperature. After this time, the reaction mixture was worked up by diluting with EtOAc/EtOH $(1: 2, \mathrm{v} / \mathrm{v})$, vortexed for $30 \mathrm{~s}$ and filtered through a syringe filter. After repeating these steps four times, the solvent was evaporated under reduced pressure, and the yield was determined using NMR using 1,3-5trimethoxybenzene as the internal standard.

\section{Acknowledgements}

Financial support from Universität Regensburg (Anschubfinanzierung von Wissenschaftlichen Projekten) and CSIC (PIE 200980I059) is gratefully acknowledged. We thank Mr Matthew Sharum for some assistance with the preliminary stability tests and initial microscopy of the beads during his internship, Dr Munmun Ghosh for preliminary experiments, Mr Joachim Rewitzer (Universität Regensburg) for assistance with the ICP-OES measurements, and Prof. Vicente Gotor-Fernández (Universidad de Oviedo) for useful discussions. D.D.D. thanks DFG for the Heisenberg Professorship Award.

\section{Notes and references}

1 R. Höfer and J. Bigorra, Green Chem., 2007, 9, 203.

2 C. Johannes and R. Verbeek, Products and applications of biopolymers, InTech, Croatia, 2012.

3 F. Quignard, F. Di Renzo and E. Guibal, Top. Curr. Chem., 2010, 294, 165.

4 D. Kühbeck, G. Saidulu, K. R. Reddy and D. D. Díaz, Green Chem., 2012, 14, 378.

5 D. Kühbeck, B. B. Dhar, E.-M. Schön, C. Cativiela, V. GotorFernández and D. D. Díaz, Beilstein J. Org. Chem., 2013, 9, 1111.

6 D. Kühbeck, E.-M. Schön, J. Bachl, V. Gotor-Fernández and D. D. Díaz, Helv. Chim. Acta, 2014, 97, 574.

7 D. Kühbeck, M. Ghosh, S. S. Gupta and D. D. Díaz, ACS Sustainable Chem. Eng., 2014, 2, 1510.

8 H. H. Tønnesen and J. Karlsen, Drug Dev. Ind. Pharm., 2002, 28, 621.

9 C. Campa, S. Holtan, N. Nilsen, T. M. Bjerkan, B. T. Stoke and G. Skjak-Bræk, Biochem. J., 2004, 381, 155.

10 S. Sharma and M. N. Gupta, Biotechnol. Appl. Biochem., 2001, 33, 161.

11 I. Roy and M. N. Gupta, Enzyme Microb. Technol., 2004, 34, 26. 12 A. Kumari, P. Mahapatra, G. V. Kumar and R. Banerjee, Bioprocess Biosyst. Eng., 2008, 31, 291.

13 A. A. Mendes, H. F. de Castro, G. S. S. Andradec, P. W. Tardioli and R. de L. C. Giordano, React. Funct. Polym., 2013, 73, 160.

14 S. Zhang, W. Shang, X. Yang, X. Zhang, Y. Huang, S. Zhang and J. Chen, J. Appl. Polym. Sci., 2014, 131, 40178, DOI: 10.1002/app.40178.

15 G. Skjåk-Bræk, H. Grasdalen and O. Smidsrød, Carbohydr. Polym., 1989, 10, 31.

16 E. Percival and R. H. McDowell, Chemistry and enzymology of marine algal polysaccharides, Academic Press, London, 1967.

17 I. Braccini and S. Pérez, Biomacromolecules, 2001, 2, 1089.

18 L. Li, Y. Fang, R. Vreeker and I. Appleqvist, Biomacromolecules, 2007, 8, 464. 
19 O. Smidsrød, Faraday Discuss. Chem. Soc., 1974, 57, 263.

20 C. Ouverx, N. Velings, M. M. Mestdagh and M. A. V. Axelos, Polym. Gels Networks, 1998, 6, 393.

21 F. Quignard, R. Valentin and F. Di Renzo, New J. Chem., 2008, 32, 1300.

22 R. Valentin, K. Molvinger, C. Viton, A. Domard and F. Quignard, Biomacromolecules, 2005, 6, 2785.

23 K. R. Reddy, K. Rajgopal and M. L. Kantam, Catal. Lett., 2007, 114, 36.

24 C. Jouannin, I. Dez, A. C. Gaumont, J. M. Taulemesse, T. Vincent and E. Guibal, Appl. Catal., B, 2011, 103, 444.

25 Y. Dong, W. Dong, Y. Cao, Z. Han and Z. Ding, Catal. Today, 2011, 175, 346.

26 C. Verrier, S. Oudeyer, I. Dez and V. Levacher, Tetrahedron Lett., 2012, 53, 1958.

27 M. Chtchigrovsky, Y. Lin, K. Ouchaou, M. Chaumontet, M. Robitzer, F. Quignard and F. Taran, Chem. Mater., 2012, 24, 1505.

28 F. Shi, J. Zheng, K. L. Xu, J. Zhang and J. Hu, Catal. Commun., 2012, 28, 23.

29 H. Yue and J. Jiang, J. Mater. Chem., 2012, 22, 23447.

30 L. Ai and J. Jiang, Bioresour. Technol., 2013, 132, 374.

31 S. V. Otari, R. M. Patil, S. R. Waghmar, S. J. Ghosh and S. H. Pawar, Dalton Trans., 2013, 42, 9966.

32 F. A. Luzzio, Tetrahedron, 2001, 57, 915.

33 C. G. van Hoogmoed, H. J. Busscher and P. De Vos, J. Biomed. Mater. Res., Part A, 2003, 67, 172.

34 K. Achelhi, S. Masse, G. Laurent, A. Saoiabi, A. Laghzizil and T. Coradin, Dalton Trans., 2010, 39, 10644.

35 T. Tripathy and R. P. Singh, J. Appl. Polym. Sci., 2001, 81, 3296.

36 T. S. Pathak, J. S. Kim, S.-J. Lee, D.-J. Baek and K.-J. Paeng, J. Polym. Environ., 2008, 16, 198.

37 K. K. Sharma, A. V. Biradar and T. Asefa, ChemCatChem, 2010, 2, 61, and references therein.

38 C. Palomo, M. Oiarbide and A. Laso, Angew. Chem., Int. Ed., 2005, 44, 3881.

39 M. E. Bunnage, S. G. Davies, C. J. Goodwin and O. Ichihara, Tetrahedron, 1994, 50, 3975.

40 U. Veith, O. Schwardt and V. Jäger, Synlett, 1996, 1181.

41 N. Shibata, T. Katoh and S. Terashima, Tetrahedron Lett., 1997, 38, 619.

42 P. M. Koskinen and A. M. P. Koskinen, Synthesis, 1998, 1075.

43 N. Ananthi and S. Velmanthi, Indian J. Chem., Sect. B: Org. Chem. Incl. Med. Chem., 2013, 52, 87, and references therein.

44 Y. Alvarez-Casao, E. Marques-Lopez and R. P. Herrera, Symmetry, 2011, 3, 220, and references therein.

45 D. Prajapati, K. C. Lekhok, J. S. Sandhu and A. C. Ghosh, J. Chem. Soc., Perkin Trans. 1, 1996, 959.
46 M. Westerhausen, Z. Anorg. Allg. Chem., 2009, 635, 13.

47 S. Harder, Chem. Rev., 2010, 110, 3852.

48 D. A. Evans, K. A. Woerpel, B. Nosse, A. Schall, Y. Shinde, E. Jezek, M. M. Haque, R. B. Chhor and O. Reiser, Org. Synth., 2006, 83, 97.

49 D. A. Evans, D. Seidel, M. Rueping, H. W. Lam, J. T. Shaw and C. W. Downey, J. Am. Chem. Soc., 2003, 125, 12692.

50 P. Agulhon, M. Robitzer, L. David and F. Quignard, Biomacromolecules, 2012, 13, 215.

51 E. Busto, V. Gotor-Fernández and V. Gotor, Org. Process Res. Dev., 2011, 15, 236.

52 J. Fan, G. Sun, C. Wan, Z. Wang and Y. Li, Chem. Commun., 2008, 3792.

53 C. V.-L. Bray, F. Jiang, X.-F. Wu, J.-B. Sortais and C. Darcel, Tetrahedron Lett., 2010, 51, 4555.

54 The following calculations were considered for the experiments using commercial sodium alginate $\left(\mathrm{Na}^{+}-\mathrm{AP}\right)$ : an average mass of $1.55 \mathrm{mg}$ per bead was determined after freeze-drying 20 randomly chosen $\mathrm{Ca}^{2+}-\mathrm{AHG}$ beads for $72 \mathrm{~h}$. This leads (under consideration of the "egg-box" model) to $M_{\text {complex }}=744.56 \mathrm{~g} \mathrm{~mol}^{-1}$. The mol\% was calculated by following equation: $\mathrm{mol} \%=\left\{\left(1.55 \times 10^{-3} \mathrm{~g} / 744.56 \mathrm{~g} \mathrm{~mol}^{-1}\right) /\right.$ $\left.0.1 \times 10^{-3} \mathrm{~mol}\right\} \times 100=2.08$. The amount of $\mathrm{Na}^{+}$-AP used in the experiments was calculated by following equation: $m=n \times \mathrm{MNa}^{+}$-alginate $=0.0004 \mathrm{~g}=0.4 \mathrm{mg}$ (with: $n=2.08 \times$ $10^{-6} ; \mathrm{MNa}^{+}$-alginate $\left.=198.11 \mathrm{~g} \mathrm{~mol}^{-1}\right)$. As expected, the yield could also be increased through the use of higher amounts of sodium alginate. However, sodium alginate is obviously more difficult to recover than the heterogeneous $\mathrm{Ca}^{2+}-\mathrm{AHG}$ beads catalysts.

55 I. Tokarev and S. Minko, Adv. Mater., 2009, 21, 241.

56 D. D. Díaz, D. Kühbeck and R. Koopmans, Chem. Soc. Rev., 2011, 40, 427.

57 T.-H. Tran-Thi, R. Dagnelie, S. Crunaire and L. Nicole, Chem. Soc. Rev., 2011, 40, 621.

58 M. Pérez-Lorenzo, B. Vaz, V. Salgueiriño and M. A. CorreaDuarte, Chem. - Eur. J., 2013, 19, 12196.

59 A. Corma, V. Fornés, R. M. Martín-Aranda and F. Rey, J. Catal., 1992, 134, 58.

60 S. E. Milner, T. S. Moody and A. R. Maguire, Eur. J. Org. Chem., 2012, 3059.

61 F. Xu, J. Wang, B. Liu, Q. Wu and X. Lin, Green Chem., 2011, 13, 2359.

62 For an interesting and relevant discussion regarding the "green" aspects of DMSO as solvent, see: M. Martí, L. Molina, C. Alemán and E. Armelin, ACS Sustainable Chem. Eng., 2013, 1, 1609, and references therein. 